\title{
Метафорическо-метонимическая интерпретация сердца \\ в казахском и тувинском языках: взаимодействие языка, анатомии и культуры
}

\author{
Канат Х. Рахимжанов, Маржан К. Акошева
}

Казахский агротехнический университет имени С. Сейфуллина, Республика Казахстан,

\author{
Зифа К. Темиргазина
}

Павлодарский государственный педагогический университет, Республика Казахстан

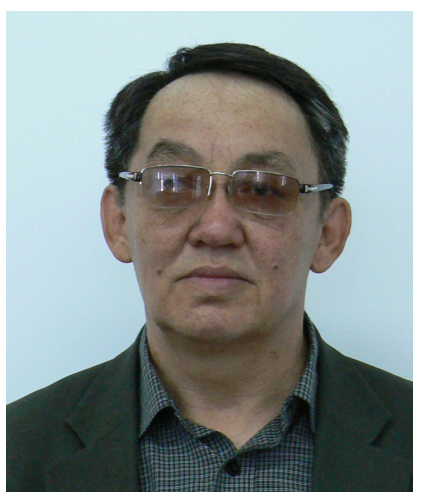

В статье исследуется метафорическая и метонимическая интерпретация понятия жүрек / чүрек - сердие в казахском и тувинском языках. Установлен набор содержательных параметров их концептуализации, по которым проведено сопоставление. Большая часть параметров говорит об универсальном характере когнитивного осмысления анатомического понятия в разных языках и культурах: жүрек / чүрек представляется сосудом для эмоций; местом обитания постоянных человеческих качеств; ему приписываются определенные цвета, не связанные с реальным иветом внутреннего органа; способность перемещаться внутри тела и быть сделанным из разных материалов. В некоторых параметрах проявляется сходство казахского и тувинского языков, обусловленное генетической общностью тюркской культуры. Идиомы сопоставляемых языков демонстрируют своеобразие концептуализации представлений о жүрек / чүрек.

Ключевые слова: тувинский язык; казахский язык; жүрек; чүрек; метафорическая интерпретация; метонимическая интерпретация; идиома
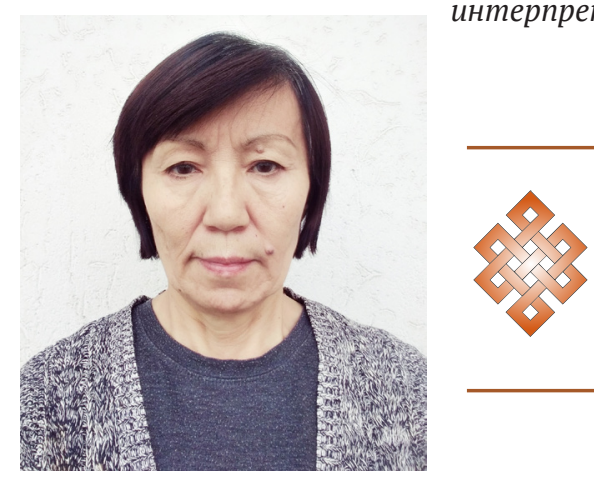

\section{Для цитирования:}

Рахимжанов К. Х., Акошева М. К., Темиргазина 3. К. Метафорическо-метонимическая интерпретация сердца в казахском и тувинском языках: взаимодействие языка, анатомии и культуры // Новые исследования Тувы. 2020, № 4. С. 261-271. DOI: www.doi.org/10.25178/nit.2020.4.18

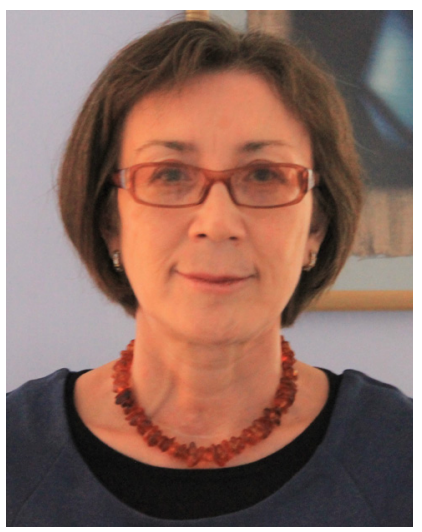

Рахимжанов Канат Хисматович - кандидат филологических наук, доцент кафедры русского и казахского языков Казахского агротехнического университета имени С. Сейфуллина. Адрес: 010011, Казахстан, г. Нур-Султан, пр. Женис, д. 62. Тел.: +7 (707) 366-72-18. Эл. адрес: kanatzhan57@mail.ru

Акошева Маржан Касымовна - кандидат филологических наук, доцент кафедры казахского и русского языков Казахского агротехнического университета имени С. Сейфуллина. Адрес: 010011, Казахстан, г. Нур-Султан, пр. Женис, д. 62. Тел.: +7 (705) 170-59-05. Эл. адрес: abitovad@inbox.ru

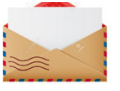
Темиргазина Зифа Какбаевна - доктор филологических наук, профессор высшей школы гуманитарных наук Павлодарского государственного педагогического уни- верситета. Адрес: 140005, Казахстан, г. Павлодар, ул. Мира, д. 60. Тел.: +7 (775) 889-2315. Эл. адрес: temirgazina_zifa@pspu.kz

RAKHIMZHANOV, Kanat Khismatovich, Candidate of Philology, Associate Professor of the Department of Russian and Kazakh Languages, S. Seifullin Kazakh Agrotechnical University. Postal address: 62 Zhenis Ave., 010011 Nur-Sultan, Republic of Kazakhstan. Tel. +7 707 3667218. Email: kanatzhan57@mail.ru_ ORCID ID: 0000-0002-6120-3069 AKOSHEVA, Marzhan Kasymovna, Candidate of Philology, Associate Professor, Department of Kazakh and Russian Languages, S. Seifullin Kazakh Agrotechnical University. Postal address: 62 Zhenis Ave., 010011 Nur-Sultan, Republic of Kazakhstan. Tel. +7 705170 5905.Email: abitovad@inbox.ru ORCID ID: 0000-0001-8393-309X

TEMIRGAZINA, Zifa Kakbaevna, Doctor of Philology, Professor, Higher School of Humanities, Pavlodar State Pedagogical University. Postal address: 60 Mira St., 140005 Pavlodar, Republic of Kazakhstan. Tel.+7 775 8892315. Email: temirgazina_zifa@pspu. $\mathrm{kz}$ ORCID ID: 0000-0003-3399-7364 


\title{
Metaphorical and metonymical interpretation of the heart in the Kazakh and Tuvan languages: an interaction of language, anatomy and culture
}

\author{
Kanat Kh. Rakhimzhanov, Marzhan K. Akosheva \\ Kazakh Agrotechnical University, Kazakhstan, \\ Zifa K. Temirgazina \\ Pavlodar State Pedagogical University, Kazakhstan
}

The article examines the metaphorical and metonymic interpretations of the concept "zhyrek/ chyrek" in the Kazakh and Tuvan languages. A set of meaningful conceptualization parameters has been developed to compare the two concepts against. Most of the parameters indicate the universal nature of the cognitive understanding of the anatomical concept in different languages and cultures: "zhyrek/ chyrek" is seen as a vessel for emotions; as the seat of permanent human qualities; certain colours, not necessarily related to the real colour of the internal organ, are attributed to it; it has an ability to move within the body and be made of different materials. In some parameters, there is a similarity between the Kazakh and Tuvan languages, due to the genetic commonality of the Turkic culture. Comparing the idioms from both languages demonstrates original conceptualizations of the notions of "zhyrek/ chyrek".

Keywords: Tuvan language; Kazakh language; zhyrek; chyrek; metaphorical and metonymic interpretation; idioms

\section{For citation:}

Rakhimzhanov K. Kh., Akosheva M. K. and Temirgazina Z. K. Metaforichesko-metonimicheskaia interpretatsiia serdtsa v kazakhskom i tuvinskom iazykakh: vzaimodeistvie iazyka, anatomii i kul'tury [Metaphorical and metonymical interpretation of the heart in the Kazakh and Tuvan languages: an interaction of language, anatomy and culture]. New Research of Tuva, 2020, no. 4, pp. 261-271. (In Russ.). DOI: www.doi.org/10.25178/nit.2020.4.18

\section{Введение}

Человек в истории философско-религиозных учений традиционно понимался как единство телесного и духовного, и если духовное (эмоциональное, психическое) неосязаемо и сложно для непосредственного изучения, то телесное, напротив, материально и открыто для наблюдения (Сухорукова, 2017: 168).

В работе исследуется фрагмент языковых картин мира казахов и тувинцев, касающийся концептуализации такого внутреннего органа, как жүрек / чүрек - ‘сердце’. Названия частей тела (соматизмы), внутренних органов человека относятся к древнейшему пласту лексического универсума языков мира, входят в базовую лексику, образуют множество устойчивых фразеологических выражений - идиом, пословиц (Temirgazina et al., 2019: 145). В семантике единиц казахского и тувинского языков - слов, идиом сохранились следы языческих, мифологических представлений древних тюрков-номадов, их традиций, обрядов и ритуалов.

Понятие жүрек не раз становилось объектом внимания в казахской лингвистике, его изучали как концепт ЖҮРЕК на материале художественных произведений (Ажибекова, 2013; Мусабекова, Культурсынова, 2018), сопоставляли с английским концептом HEART/ SOUL (Султангубиева, 2011ab¹),

1 Также: Кобландина К. С. Семантические особенности концептов «жан/soul», жүрек/heart [Электронный pecypc] // Publishing house Education and Science s.r.o. URL: http://www.rusnauka.com/36_PVMN_2012/Philologia/9_123338.doc.htm (дата обращения: 06.05.2020). 
рассматривали многозначность слова жүрек в произведениях аль-Фараби (Авад, Ержан, Анарбаев, 2016), выявляли его дидактическую роль в учебном процессе (Temirgazina, Khamitova, Orasalinova, 2016) и т. д.

В тувинском языке понятие чүрек рассматривалось в работе Б. К. Ондар (Ондар, 2010) как соматизм в составе фразеологических единиц в сопоставлении с фразеологизмами русского языка. Т. В. Жукова отмечает важность и недостаточную изученность сопоставительного аспекта тувинской фразеологии: «В тувинском языкознании первые теоретические исследования фразеологизмов относятся к 60-70 гг. $\mathrm{XX}$ века. Нужно отметить, до сих пор очень мало сделано в сравнительном изучении тувинской фразеологии. Между тем эта проблема весьма актуальна» (Жукова, 2017: 26).

Сопоставительный анализ концептуализации анатомического понятия жүрек / чүрек с помощью универсального когнитивного механизма аналогии - метонимизации и метафоризации - позволяет выявить общность и различие в наивной трактовке (житейских представлениях) указанного органа носителями генетически родственных казахской и тувинской культур. Содержательные параметры, на основе которых проводится сопоставление, были вычленены в ходе семантического, этимологического и лингвокультурного анализа языковых единиц с метонимическим и метафорическим значением.

Языковые единицы для анализа (слова и идиомы с компонентом жүрек / чүрек) были отобраны из толковых и фразеологических словарей, включая двуязычные: казахского языка (Бектаев, 1999; Кенесбаев, 2007¹), тувинского языка (Тувинско-русский словарь, 1968; Русско-тувинский словарь, 1980).

\section{Локализация эмоциий и чувств в сердце}

Сердце является основным внутренним органом в наивно-анатомических представлениях большинства народов, оно представляется в них олицетворением психической, духовной жизни человека. Универсальным для языков мира является установление связи между внутренними органами и ментальным миром человека (см. об этом: Урысон, 20032). «Исследования эмоций и отдельных эмоциональных концептов, осуществляемые лингвистами и лингвокультурологами в рамках разных лингвокультур, позволяет утверждать, что во все времена человеческое сознание стремится связать переживаемые чувства и эмоции с какими-либо частями человеческого тела, установить место их “локализации” внутри человека» (Заяц, 2017: 4). Таким образом, каждый внутренний орган является местом «обитания» каких-либо эмоций, качеств человека и других ментальных явлений. Связь, устанавливаемая между внутренним органом и ментальными процессами, носит идиоэтнический характер и отражает культурно-специфические взгляды народа. Метафора и метонимия являются неотъемлемым свойством в языковом представлении этой взаимосвязи (Temirgazina, Bakhtikireeva, Sinyachkin, 2017).

В соответствии с названной универсальной тенденцией - локализацией ментальных процессов во внутренних органах человека, сердце метонимически осмыслялось казахами как место обитания определенных чувств, помыслов, желаний:

волнения, беспокойства - жүрегі қобалжу, жүрегі мұздау (в значении “волноваться; беспокоиться”);

переживаний - жүрегі сыздау (дословно ‘болеть душой’);

желания - жүрегімен берілу (в значении “предаться сердцем”);

спокойствия - жүрек орнына түсу (дословно 'сердце встало на место’ в значении “успокоиться; перестать сомневаться”);

страха - жүрегі су/зу ету (дословно ‘сердце екнуло/встрепенулось' в значении “испугаться от неожиданности”), жүрегі шайлығу (в значении “испугаться; не иметь больше желания делать”), жүрегі тас төбесіне шықты (дословно “сердце подскочило к темени’ в значении “сильно испугаться”) (Кенесбаев, 2007: 121).

В родственном тувинском языке чүрек также представляется средоточием чувств и желаний:

любви - чүрээн бээр (в значении “крепко любить”);

спокойствия - чүрээ оожургаар (в значении “успокоиться”);

${ }^{1}$ А также словаре: Қазақша-орысша сөздік. URL: https://sozdik.kz/ru (дата обращения: 20.03.2020).

${ }^{2}$ The Body in Description of Emotion: Cross-linguistic Studies. Pragmatics \& Cognition, 2002. 10:1/2. Special Issue /

Nick J. Enfield, Anna Wierzbicka (eds). Benjamins. 367 p. 
предчувствия - чүрээ эндевээн (в значении “сердце чувствует”);

страха - чүрээ аксынга келир (дословно “сердце подкатило ко рту’ в значении “перепугаться”), чүрек өлүр (дословно ‘сердце отмирает’ в значении “получил урок, проучен, наказан; стал пугливым”) (Тувинско-русский словарь, 1968: 551);

следования зову сердца - чүректи дужаап болбас (в значении “сердцу не прикажешь”), чүрээн тудар (дословно ‘взять за сердце’ в значении “покорить сердце”) (Русско-тувинский словарь, 1980: 529); чүлду-чүрээм кударалга туттура берди (дословно 'сердце мое стало невеселым, грусть-тоска одолели его') (Ондар, 2010: 127).

В тюркских языках происходит отождествление эмоциональных переживаний с сердцем, которое воспринимается как орган, физически реагирующий на внешние воздействия. При этом сильные и неожиданные эмоции описываются как попытка сердца выскочить через рот:

тув. чүрээ палыт дээн (дословно ‘сердце оборвалось'), чүрээ аксынга келген (дословно 'сердце подкатило ко рту’ в значении “сильно испугаться”) (Русско-тувинский словарь, 1980: 529);

каз.: жүрегім аузыма тығылды (дословно 'сердце спряталось во рту’ в значении “сильно испугаться") ${ }^{1}$.

Фразеологические эквиваленты данной семантической категории схожи по смысловой, стилистической и грамматической структуре. В их составе присутствует обязательный компонент аксы/ аузы (дословно 'рот').

\section{Жүрек / чүрек как место обитания человеческих качеств}

В сердце могли заключаться, с точки зрения наивно-анатомических взглядов казахов, и определенные качества человека, в первую очередь смелость, храбрость:

жүрегінің түгі бар адам (дословно ‘человек с ворсом на сердце’) - смелый, бесстрашный человек; $121)$

жүрек жұтқан (дословно ‘проглотивший сердце’) - смелый, храбрый, отважный (Кенесбаев, 2007:

жүректі (дословно 'сердечный’) - смелый, храбрый;

жүректі болу (дословно ‘быть сердечным’) - быть смелым;

жүректілік (дословно 'сердечность') - смелость, храбрость.

См. также пословицу: Ерлік білекте емес, жүректе (дословно 'Мужество не в силе рук, а в сердце’). Соответственно, человек, лишенный сердца, характеризовался как “трусливый, робкий, несмелый»: жүрексіз (дословно ‘лишенный сердца, без сердца') (Бектаев, 1999: 213). И в тувинском языке сердце является местом обитания смелости, например, слова чүреккир, чүректиг - смелый, храбрый, бесстрашный (Тувинско-русский словарь, 1968: 551). Интересно отметить, что в тувинском языке отсутствие сердца чүрек чок (дословно ‘без сердца'), в отличие от казахского языка, обозначает другое качество человека - «ленивый» (там же: 551). О чүрээ чок в значении «ленивый» пишет и В. И. Рассадин, обращая внимание на монгольское происхождение слова (Рассадин, 1988: 63).

Семантика казахской идиомы жүрек жұқан (дословно ‘проглотивший сердце’ в значении “смелый, храбрый, отважный”) восходит к мифологическим представлениям древних тюрков о животныхтотемах. Они осуществляли ритуал жертвоприношения и поедания животного-тотема, целью которого было установление порядка, гармонии, иерархии в окружающем их мире. Исследователи мифологии тюрков Южной Сибири отмечали: «Глубинная связь символики еды и жертвы заставляет вспомнить нас мифы о сотворении мира, согласно которым Вселенная возникает в результате разделения на части того, что было раньше единым. Эта операция сопровождается утверждением порядка, структуры, а в социальном плане - иерархии, соподчинения. Коллективная трапеза с расчленением туши животного... быть может восходит к неким древним ритуалам, базирующимся на представлениях о первой жертве (первопредке), из расчлененного тела которой возник Космос» (Традиционное мировоззрение ... , 1990: 43). Как пишет культуролог 3. Наурзбаева, «Расчленение

\footnotetext{
${ }^{1}$ Қазақша-орысша сөздік. URL: https://sozdik.kz/ru (дата обращения: 20.03.2020).

${ }^{2}$ Наурзбаева, 3. (2009) Казахский той как жертвоприношение тотема. URL: https://express-k.kz/news/zhizn/

kazakhskiy_toy_kak_zhertvoprinoshenie_totema-81645 (дата обращения: 06.08.2020).
} 
жертвенных животных использует анатомический код для оформления социальных структур: род осмысливается как единое тело, его члены как части тела жертвенного животного»².

Таким образом, съесть, проглотить сердце животного есть элемент древнего тюркского ритуала, сведения о котором сохранились в преданиях, обычаях. У казахов существует понятие жерік, «когда беременная женщина хочет отведать какой-то особенной пищи. Считалось, что этой пищи жаждет ребенок в утробе, выполнение этого желания обеспечивает полноценность его развития, предопределяет будущее. В эпосе будущая мать батыра обычно желала отведать сердца леопарда, тигра или волка» ${ }^{1}$. Батыр - это отважный, сильный воин, который проглотил в утробе матери сердце тотемного животного, обычно волка, и это дало ему отвагу, храбрость и силу.

Следует добавить, что в казахской наивной анатомии отвага и храбрость человека отождествлялись с сердцем мужчины, батыра: ер жүрек (дословно “сердце мужчины’ в значении “смелый”). В тувинском языке также встречается фразеологизм эр чуректиг (дословно 'с мужским сердцем') в значении “смелый”, ”храбрый”, но так обычно говорят о женщине (Ондар, 2010: 129). Хотя эти фразеологизмы схожи стилистически, грамматически, у тувинцев идиома гендерно ориентирована ${ }^{2}$, таким образом оценивалась смелость женщины: “храбрая, как мужчина”.

В сердце, помимо храбрости, смелости, также обитает доброта, бескорыстие.

Казахский язык:

Жақсылық - жүректен, жамандық - білуектен (дословно 'Доброта - от сердца, подлость - от силы’);

Ауызын ашса жүрегі көрінеді (дословно 'Откроет рот - видно сердце') в значении “добрый, бескорыстный"з;

тувинский язык:

буянныг чүрек / чагбан чүректіг “добрый, отзывчивый” (там же: 130).

Сердце является носителем чистоты, мягкости, нежности, эти качества обозначаются прилагательными, которые сочетаются с существительным жүрек: таза / жұмсақ / нәзік жүрек4.

В тувинской наивной анатомии сердце может быть средоточием негативных качеств: трусости, легкомысленности, склонности к шалостям. Так, расположение сердца во рту является симптомом трусости: ааксында чуректиг (дословно 'с сердцем во рту'). А если в сердце поселится воздух, то обладатель его характеризуется как легкомысленный человек: чүрээ хейлиг хей-дир (дословно ‘в его сердце есть воздух') (там же: 129). Безэквивалентными национально-специфическими являются тувинские идиомы, основанные на представлении о том, что сердце может завшиветь, в нем могут поселиться паразиты: чүрээ быдыыр (дословно 'сердце его завшивеет') в значении “валять дурака, шалить, вести себя легкомысленно”), чүрээ быттыг (дословно “сердце его завшивленное') в значении “дурашливый, шаловливый, легкомысленный”.

Считаем важным отметить типичную для тувинской лингвокультуры взаимосвязь сердца и умственного состояния человека, которая четко прослеживается в семантике ряда идиом, например, согласно словарю, выражение чүрек аарыы означает не только болезнь сердца, но и сумасшествие; чүрээ аарыг - сумасшедший; крайне легкомысленный; неразумный; чүрээ аарыыр - лишаться ума, сходить с ума; поступать крайне легкомысленно, дурить; чүрээ багай - слабоумный (Тувинско-русский словарь, 1968: 551).

\section{Сердце - это сосуд для эмоции-жидкости}

Многие исследователи отмечали такую особенность в когнитивном механизме метафоризации эмоций, когда они описываются как жидкость, а внутренний орган - как сосуд для эмоции-жидкости (Davitz, 1969; Kövecses, 1989; Клобуков, 1997 и др.). Иначе говоря, сердце мыслится как сосуд, который может наполняться различными эмоциями-жидкостями.

1 Наурзбаева, 3. (2009) Казахский той как жертвоприношение тотема. URL: https:/express-k.kz/news/zhizn/ kazakhskiy_toy_kak_zhertvoprinoshenie_totema-81645 (дата обращения: 06.08.2020).

${ }^{2}$ См. о гендерных стереотипах в тувинской культуре: Егорова, Кондакова, Кужугет, 2020.

${ }^{3}$ Қазақша-орысша сөздік. URL: https://sozdik.kz/ru (дата обращения: 20.03.2020).

${ }^{4}$ Там же.

${ }^{5}$ Там же. 
Такая метафорическая модель больше свойственна тувинскому языкам и в меньшей степени казахскому. В тувинском языке сердце является хранилищем-сосудом различных чувств: чүрээнде шыгжап чоруур (дословно 'хранит в сердце') (Ондар, 2010: 127). В казахском языке сердце может быть наполнено только обидой: ренішке толы жүрек'.

Подобное различие в интерпретации сердца связано с тем, что в казахской наивной анатомии очень значимыми и важными представляются другие внутренние органы, которые и являются носителями остальных эмоций, например, печень - носитель родственной любви, доверия, сопереживания; легкие - ненависти, раздражения, обиды.

\section{Цветовая и динамическая характеристика сердца}

Сердце может иметь цвет, по мнению носителей разных культур, причем приписывание определенного цвета имеет культурно-обусловленный характер и не связан с реальным цветом внутреннего органа. Например, в наивной анатомии казахов сердце может быть белым и черным и, соответственно, обозначать различные нравственные качества человека: ақ жүрек (дословно 'белое сердце') в значении “добрый, мягкосердечный, искренний”; қара жүрек (дословно 'черное сердце') в значении “безжалостный, жестокосердный”. Аналогичная цветовая характеристика свойственна сердцу и в тувинской наивной анатомии: ак чүрек (дословно “белое сердце') в значении “добрый, искренний”; кара чүрек (дословно 'черное сердце') в значении “жестокий, жестокосердный”.

Подобное сходство в родственных тюркских языках основано на близкой культурной трактовке белого и черного цвета как важнейших цветовых символов в восприятии окружающего мира.

Сердце, по мнению казахов, способно перемещаться вверх, например, подниматься к темени, прятаться во рту, потом возвращаться вниз на место. В тувинском языке сердце также может передвигаться вверх ко рту и может падать вниз. Мы уже упоминали выше, что сильные и неожиданные эмоции описываются как попытка сердца выскочить через рот. Направление движения сердца при неожиданном испуге описывается по-разному в казахском и тувинском языках:

в каз. - вверх до темени (жүрегі тас төбесіне шықты, дословно 'сердце подскочило к темени') (Кенесбаев, 2007: 121);

в тув. - вверх ко рту (чүрээ аксынга келген - дословно 'сердце подкатило ко рту'), вниз (чүрээ палырт дээн - дословно 'сердце упало’) (Русско-тувинский словарь, 1980: 529).

\section{Замена функций другого внутреннего органа}

Важно отметить такую специфическую черту наивной анатомии казахов и тувинцев, когда жүрек / чүрек сближается по функциям с желудком и способно испытывать физиологические чувства тошноты, рвоты, сильного голода, см., например, идиомы -

казахские:

жүрегі айну (дословно 'сердце отказывается’) - испытывать тошноту, тошнить;

жүрегі күпті болу (дословно 'иметь сердце') - испытывать чувство тошноты от жирной пищи;

жүрегі қараю (дословно 'сердце почернело') - кто-либо очень голоден; сильно проголодаться;

жүрек жалғау (дословно 'поддержать сердце') - перекусить, слегка утолить голод;

жүрегім лоблып тұр (дословно 'у меня сердце тошнит') - меня тошнит (Кенесбаев, 2007: 121);

тувинские:

чүрээ аарыыр (дословно 'сердце отказывается') - тошнить от съеденного сала или выпитого спиртного;

чүрекке дээр (дословно 'задеть за сердце') - вызывать тошноту (о съеденном сале), здесь есть и значение “надоесть” (о работе) (Ондар, 2010: 131).

Г. И. Кабакова пишет о том, что «в некоторых традициях органы пищеварения и прежде всего желудок сближаются и даже смешиваются с сердцем, в других - с легкими» (Кабакова, 2015: 133). Фразеологические единицы, сохраняющие “физиологическую” семантику сердца, основаны не на современных научных знаниях о данном органе, а на древних анатомических воззрениях, восходящих к языческим мифам и обрядам. 


\section{Принадлежность сердца животным}

Человек может обладать сердцем какого-либо животного и, соответственно, наделяться характеристиками, которые ассоциируются в национально-культурных символических представлениях с этим животным. Например:

арыстан жүрегі в значении “храбрый человек” (Султангубиева, 2011b: 197);

қоян жүрегі1, койгун чӥректиг в значении “трусливый человек” (Ондар, 2010: 130).

В казахском и тувинском языках заяц является эталоном трусости, а эталон храбрости для казахов лев. Соответствующие ассоциации, связанные с этими животными, закреплены во фразеосемантике сопоставляемых языков. В казахской культуре также функционирует идиома ит жүрек (дословно “собачье сердце') в значении “капризный, переменчивый характер”, в которой собака предстает эталоном капризности, непостоянства человека.

Физиологическое состояние сердца при волнении, расстройстве сравнивается в казахском языке с гарцеванием коня: жүрек аттай тулап тұр (дословно 'сердце как конь гарцует') в значении “сердце трепещет” (Кенесбаев, 2007: 120).

\section{Физические свойства сердцза (материал, твердость, температура)}

Сердце в наивной анатомии казахов, тувинцев представляется сделанным из разных материалов, прежде всего золота: алтын жүрек / алдын чүректиг. Золото во многих культурах является эталоном ценности, как материальной (богатства, плодородия), так и духовной (божественного промысла, мудрости, величия). Лингвокультурная аксиологическая коннотация ценности перекрывает физическое свойство твердости металла и способствует формированию положительно окрашенной семантики “доброта, щедрость, милосердие”. Сердце в воззрениях казахов и тувинцев может быть сделано из камня: тас жүрек, тас чүректіг в значении “черствый, беспощадный, жестокий, безжалостный”; а казахи также считают, что сердце может быть сделанным изо льда: мұз жүрек в значении “бесчувственный, недобрый, немилосердный, холодный человек” (Бектаев, 1999: 436).

Носители казахского и тувинского языков полагают, что сердце может иметь такие свойства, как мягкость, и обладать температурными показателями - быть теплым, горячим, холодным:

в казахском:

жұмсақ жүрек (дословно 'мягкое сердце' в значении «ласковый; добрый»);

жылы жүрек (дословно 'теплое сердце’ в значении “доброжелательный, радушный, мягкий”);

ыстық жүрек (дословно 'горячее сердце' в значении “любящий”)';

в тувинском: 129).

нымзах чүректіг (дословно ‘мягкое сердце’ в значении “ласковый; мягкий характер”) (Ондар, 2010:

В тувинском языке чүрек представляется отчуждаемым от тела предметом, который можно взять в руки, отдать кому-либо: чүрээн хөлзедир, чүрээн бээр (дословно ‘брать сердце'), чүрээн тудар (дословно 'взять за сердце') (Русско-тувинский словарь, 1980: 529).

В тувинском языке также отмечена активно действующая метонимическая модель "внутренний орган вместо места”, в которой сердце чүрек обозначает центр чего-либо: Москва - бистиң Төрээн чуртувустуң чүрээ (“Москва - сердце нашей Родины”) (Тувинско-русский словарь, 1968: 551).

\section{Сравнение интерпретации понятия жүрек / чүрек в казахском, тувинском языках}

Когнитивное осмысление сердца в соответствии с выявленными выше в анализе языковых единиц параметрами представлено ниже в таблице 1.

${ }^{1}$ Қазақша-орысша сөздік. URL: https://sozdik.kz/ru (дата обращения: 20.03.2020).

2 Там же. 


\section{НОВЫЕ ИССЛЕДОВАНИЯ ТУВЫ}

www.nit.tuva.asia

Таблица 1. Параметры когнитивного осмысления понятия жүрек / чүрек в казахском и тувинском языках

Table 1. Parameters of cognitive understanding of the notion of zhyrek / chyrek in Kazakh and Tuvan languages

\begin{tabular}{|c|c|c|c|}
\hline & \multirow[b]{2}{*}{ Параметры сравнения } & \multicolumn{2}{|c|}{ Язық } \\
\hline & & $\begin{array}{l}\text { Казахский } \\
\text { ЖҮРЕК }\end{array}$ & $\begin{array}{l}\text { Тувинский } \\
\text { ЧҮРЕК }\end{array}$ \\
\hline 1 & $\begin{array}{c}\text { Локализация позитивных } \\
\text { эмоций }\end{array}$ & радость, спокойствие & любовь, спокойствие \\
\hline 2 & $\begin{array}{c}\text { Локализация негативных } \\
\text { эмоций }\end{array}$ & $\begin{array}{c}\text { волнение, беспокойство, } \\
\text { переживания, страх, испуг }\end{array}$ & $\begin{array}{c}\text { предчувстие событий, страх, испуг, } \\
\text { возбуждение, грусть }\end{array}$ \\
\hline 3 & $\begin{array}{c}\text { Локализация позитивных } \\
\text { человеческих качеств }\end{array}$ & $\begin{array}{l}\text { смелость, храбрость, доброта, } \\
\text { нежность, мягкость, чистота }\end{array}$ & $\begin{array}{c}\text { смелость, храбрость, доброта, } \\
\text { мягкость, отзывчивость }\end{array}$ \\
\hline 4 & $\begin{array}{c}\text { Локализация негативных } \\
\text { человеческих качеств }\end{array}$ & & легкомыслие, трусость \\
\hline 5 & $\begin{array}{c}\text { Взаимосвязь сердца и } \\
\text { умственного состояния } \\
\text { человека }\end{array}$ & & $\begin{array}{c}\text { болезнь сердца означает } \\
\text { сумасшествие, слабоумие }\end{array}$ \\
\hline 6 & $\begin{array}{l}\text { Способность к } \\
\text { перемещению }\end{array}$ & $\begin{array}{c}\text { вверх к темени при неожиданном } \\
\text { испуге; вверх ко рту; вернуться на } \\
\text { место }\end{array}$ & $\begin{array}{c}\text { вверх до рта при неожиданном } \\
\text { испуге; вниз }\end{array}$ \\
\hline 7 & $\begin{array}{c}\text { Возможность отсутствия у } \\
\text { человека }\end{array}$ & $\begin{array}{l}\text { возможно (журеқсіз в значении } \\
\text { “трусливый, робкий, несмелый”) }\end{array}$ & $\begin{array}{c}\text { возможно (чүрээ чок в значении } \\
\text { “ленивый”) }\end{array}$ \\
\hline 8 & $\begin{array}{c}\text { Сосуд для эмоций- } \\
\text { жидкостей }\end{array}$ & сосуд для обиды & емкость-хранилище для эмоций \\
\hline 9 & Способность иметь цвет & $\begin{array}{c}\text { способно иметь белый и черный } \\
\text { цвет: ақжүрек, қара жүрек }\end{array}$ & $\begin{array}{c}\text { способно иметь белый и черный } \\
\text { цвет: ак чүрек, кара чүрек }\end{array}$ \\
\hline 10 & $\begin{array}{c}\text { Замена функций другого } \\
\text { органа }\end{array}$ & заменяет функции желудка & $\begin{array}{c}\text { заменяет } \\
\text { функции желудка }\end{array}$ \\
\hline 11 & $\begin{array}{c}\text { Принадлежность } \\
\text { животному }\end{array}$ & принадлежит льву, зайцу, собаке & принадлежит зайцу \\
\hline 12 & $\begin{array}{c}\text { Сердце как отчуждаемый/ } \\
\text { отделяемый предмет }\end{array}$ & & сердце можно отдать, взять в руки \\
\hline 13 & $\begin{array}{c}\text { Способность быть } \\
\text { сделанным из металла, } \\
\text { камня и др. веществ }\end{array}$ & $\begin{array}{c}\text { может быть сделанным из золота, } \\
\text { камня }\end{array}$ & $\begin{array}{c}\text { может быть сделанным из золота, } \\
\text { камня }\end{array}$ \\
\hline 14 & $\begin{array}{c}\text { Обладание свойством } \\
\text { мягкости/твердости }\end{array}$ & способно быть мягким & способно быть мягким \\
\hline 15 & $\begin{array}{l}\text { Температурные } \\
\text { характеристики }\end{array}$ & может быть теплым, горячим & \\
\hline 16 & $\begin{array}{c}\text { Обозначение локализации } \\
\text { чего-либо в центре }\end{array}$ & & обозначает центр чего-либо \\
\hline
\end{tabular}




\section{Заключение}

Значимость сердца в наивной анатомии носителей тюркоязычных культур подтверждается комплексом признаков, согласно которым осуществляется их метафорическо-метонимическая интерпретация. Выделенные содержательные параметры дают возможность более детально взглянуть на общность и различие интерпретации жүрек / чүрек носителями казахской и тувинской культур. Сопоставительный анализ в двух родственных языках с выделением семантических параметров позволяет сделать следующие выводы.

Сердце подвергается многоаспектной, разносторонней концептуализации в указанных культурах, о чем свидетельствует общее число выделенных параметров - 16. Количество параметров, в которых выражается его когнитивное метафорическо-метонимическое осмысление, в казахском языке - 12 , тувинском -15 .

Подчеркнем, что количество параметров, по которым осуществляется метафорическо-метонимическая интерпретация чүрек, свидетельствует о важности этого понятия в тувинской лингвокультуре. Казахский и тувинский языки, в силу генетической общности и сходства культур, имеют общие признаки в интерпретации такого внутреннего органа, как сердце: «замена функций другого органа», «способность быть сделанным из других веществ», «обладание свойством мягкости / твердости», цветовая и динамическая характеристики. Действительно, с точки зрений казахов и тувинцев, сердце выполняет некоторые функции желудка - передает голод, насыщение, переедание, тошноту; оно способно иметь белый и черный цвет; передвигаться вверх ко рту и вниз, может быть сделано из камня и золота.

Различие касается таких признаков, как «взаимосвязь сердца и умственного состояния человека», «обозначение локализации чего-либо», «сердце как отчуждаемый предмет», которые свойственны тувинскому языку и отсутствуют в казахском, а также признака «способность иметь температуру», который обнаруживается в казахском языке и отсутствует в тувинском. В представлениях казахов сердце не может содержать негативные человеческие качества, они также не считают, что в сердце могут заключаться такие сильные негативные эмоции, как ненависть, гнев, скорбь, злоба, печаль. Ограничена реализация параметра «сосуд для эмоций-жидкостей»: сердце может быть сосудом только для одной эмоции-жидкости - обиды, в то время как в тувинском - для большого количества эмоцийжидкостей: любви, ненависти, обиды, скорби, печали, счастья, радости, грусти. Параметр «возможность отсутствия у человека» также реализуется у носителей казахской и тувинской культуры поразному: отсутствие сердца интерпретируется у тувинцев как леность, у казахов - как трусость.

Жүрек - не самый важный орган в казахской наивной анатомии, в которой главным органом признается бауыр (печень) (Мусабекова, Культурсынова, 2018), в отличие от тувинской. Это объясняется следующими причинами: сердце не означает важнейшего для социально-экономического уклада казахов понятия, как родство, и, соответственно, не выступает эквивалентом высшей ценности в системе национально-культурных ценностей.

Таким образом, надо признать, что языковые единицы, возникшие в результате действия когнитивного механизма аналогии (метафоры и метонимии) при осмыслении жүрек / чүрек как внутреннего органа человека, в значительной степени основаны не на научных знаниях о физиологии и анатомии, а на древних мифологических, языческих воззрениях носителей лингвокультуры.

\section{СПИСОК ЛИТЕРАТУРЫ}

Авад, Б. 3., Ержан, Қ. С., Анарбаев, Н. С. (2016) Әбул Қасым ал-Фарабидың (Фариаби) шығармасындағы жүрек түсінігі // Вестник Карагандинского университета. Серия «История. Философия». № 2 (82). С. 11-118. (На каз. яз.)

Ажибекова, М. Е. (2013) Абай поэзиясындағы «жүрек» концептісінің қолданылуын нейролингвистикалық бағдарлаутұрғысынан талдау // «Ғылым жене білім - 2013» атты студенттер мен жас ғалымдардың VIII Халықаралық ғылыми конференциясының баяндамалар жинағы. Material list of Eighth International Scientific Conference for students and young scientists «Science and education - 2013». Сборник материалов VIII Международной научной конференции студентов и молодых ученых «Наука и образование - 2013». 10 апреля 2013 года. Астана : ЕНУ им. Л. Гумилева. Т. 4.338 с. С. 6-9.

Бектаев, К. Б. (1999) Үлкен қазақша-орысша, орысша-қазақша сөздік [Большой казахско-русский, русско-казахский словарь]. Алматы : Қазына. 704 с. (На каз. яз.)

Егорова, А. И., Кондакова, А. П., Кужугет, М. А. (2020) Гендерные стереотипы в тувинских пословицах и поговорках // Новые исследования Тувы. № 1. С. 19-34. DOI: https://doi.org/10.25178/nit.2020.1.2 
Жукова, Т. В. (2017) Фразеологические обороты с компонентом «животное» в сопоставительном аспекте // Методология и практика научных исследований / отв. ред. М. С. Власов. Бийск : АГГПУ им. В. М. Шукшина. 49 с. С. 26-28.

Заяц, И. Г. (2017) Представления о «локализации» эмоций в средневековом языковом сознании (на материале средневековой немецкой литературы) // Филологические науки в России и за рубежом : Материалы V Международной научной конференции / отв. ред. Г. А. Кайнова, Е. И. Осянина. СПб. : Свое издательство. 82 с. С. 4-6.

Кабакова, Г. И. (2015) «Наивная анатомия» в зеркале языка: пищеварительный тракт [Электронный ресурс] // Этнолингвистика. Ономастика. Этимология : материалы III Междунар. науч. конф. Екатеринбург, 7-11 сентября 2015 г. Екатеринбург : Изд-во Урал. ун-та.С. 133.URL: http://hdl.handle.net/10995/38370 (дата обращения: 23.02.2020).

Кеңесбаев, I. К. (2007) Фразеологиялық сөздік [Фразеологический словарь]. Алматы : ҚазАқпарат. 356 б. (На каз. яз.).

Клобуков, П. Е. (1997) Метафора как концептуальная модель формирования языка эмоций // Язык, сознание, коммуникация : сборник статей / ред. В. В. Красных, А. И. Изотов. М. : Филология. Вып. 2. 124 с. С. 41-47.

Мусабекова, У. А., Культурсынова, Ф. Б. (2018) Национально-культурная специфика репрезентации концепта "ЖYРЕК" (на материале произведений М. Жолдасбекова) // Neophilology. Vol. 4, no. 16. P. 15-19. DOI: https://doi. org/10.20310/2587-6953-2018-4-16-15-19

Ондар, Б. К. (2010) Слово «Сердце» («Чүрек») в составе фразеологических и нефразеологических оборотов русского и тувинского языков // Вестник Тувинского государственного университета. Социальные и гуманитарные науки. № 1. С. 124-132.

Рассадин, В. И. (1988) О тюркском влиянии на развитие говора нижнеудинских бурят // Проблемы монгольского языкознания: сборник научных трудов / отв. ред. Л. Д. Шагдаров Новосибирск : Наука. 159 с. С. $62-75$.

Русско-тувинский словарь (1980): 32000 слов = Орус-тыва словарь : 32000 состуг / под ред. Д. А. Монгуша. Москва : Русский язык. 560 с.

Султангубиева, А. А. (2011а) Діни әлемдегі жүрек концептінің қызметі (қазақ, орыс, ағылшын тілдерінің материалдары бойынша) // Вестник КазНУ. Серия филологическая. № 2(132). С. 165-167. (На каз. яз.)

Султангубиева, А. А. (2011b) Жүрек концептіндегі «адам жағдайының физикалық көріністері» (қазақ, орыс, ағылшын тілдерінің материалдары бойынша) // Вестник КазНУ. Серия филологическая. № 4 (134). С. 195-198. (На каз. яз.)

Сухорукова, Ю. С. (2017) К вопросу о наивной анатомии сердца во французской фразеологии // Филологические науки. Вопросы теории и практики. № 3 (69): в 3-х ч. Ч. 3. С. 168-170.

Традиционное мировоззрение тюрков Южной Сибири. Знак и ритуал (1990) / Сагалаев А. М., Октябрьская И. В. Новосибирск : Наука. Сиб. Отделение. 200 с.

Тувинско-русский словарь (1968) / под ред. Э. Р. Тенишева. М. : Советская энциклопедия. 648 с.

Урысон, Е. В. (2003) Проблемы исследования языковой картины мира: Аналогия в семантике. М. : Языки славянской культуры. 224 с.

Davitz, J. R. (1969) The Language of Emotion. New York : Academic Press. 208 p.

Kövecses, Z. (1989) Emotion Concepts. Frankfurt-am-Main : Springer Verlag. 230 p.

Temirgazina, Z., Khamitova, G., Orazalinova, K. (2016) Didactic Features of a Learner's English-Russian Dictionary of Biology Development // Research Journal of Pharmaceutical, Biological and Chemical Sciences. Vol. 7(2). P. 317-326.

Temirgazina, Z. K., Bahtikireeva, U. M., Sinyachkin, V. P. (2017) Artifacts as a source of russian and kazakh Zoological terms // Information. Vol. 20, No. 4(A). Pp. 2325-2336.

Temirgazina, Z., Akosheva, M., Shakaman, Y., Shaharman, A., Kurmanova, Z., Kairova, M. (2019) Metaphors in Anatomical Terminology // Space and Culture, India. 7:1. P. 143-153. DOI: https://doi.org/10.20896/saci.v7i1.528

\section{REFERENCES}

Avad, B. Z., Yerzhan, K. S. and Anarbaev, N. S. (2016) Abul Қаsym al-Farabidał (Fariabi) shygarmashyndagy zhurek tusinigi [The concept of the heart in the works of Abyl Kasym al-Farabi]. Bulletin of the Karaganda University. Issue "History. Philosophy”, no. 2 (82), pp. 11-118. (In Kaz.).

Azhibekova, M. E. (2013) Abay poetry sindaky 'zhurek'concept isinin koldanyluyn neurolinguistics bagdarlau tyrgysynan taldau. In: Sat. materials of the $8^{\text {th }}$ International research conference "Science and Education - 2013". Astana, ENU named after L. Gumilyov. Vol. 4. Pp. 6-9. (In Kaz.).

Bektaev, K. B. (1999) Ulken kazaksha-oryssha, oryssha-kazaksha sozdik [A large Kazakh-Russian and Russian-Kazakh dictionary]. Almaty, Kazyna.

Egorova, A. I., Kondakova, A. P. and Kuzhuget, M. A. (2020) Gendernyye stereotipy v tuvinskikh poslovitsakh i pogovorkakh [Gender stereotypes in Tuvan proverbs and sayings]. New Research of Tuva. no. 1, pp. 19-34. DOI: https://doi. org/10.25178/nit.2020.1.2 (In Russ.). 
Zhukova, T. V. (2017) Frazeologicheskiye oboroty s komponentom «zhivotnoye» v sopostavitel'nom aspekte [Phraseological turns with the "animal" component in a comparative aspect]. In: Metodologiya i praktika nauchnykh issledovaniy [Methodology and practice of academic research]. Ed. by M. S. Vlasov. Biysk, AGGPU im. V. M. Shukshina. 49 p. Pp. 26-28. (In Russ.).

Zayats, I. G. (2017) Predstavleniya o «lokalizatsii» emotsiy v srednevekovom yazykovom soznanii (na materiale srednevekovoy nemetskoy literatury) [Representations of "localizing" emotions in medieval linguistic consciousness: the case of medieval German literature]. In: Filologicheskiye nauki v Rossii i za rubezhom [Philological disciplines in Russia and abroad]: Proceedings of the $5^{\text {th }}$ International research conference. Ed. by G. A. Kainov and E. I. Osyanin. St. Peterburg, Svoe izdatel'stvo. 82 p. Pp. 4-6. (In Russ.).

Kabakova, G. I. (2015) “Naivnaya anatomiya” v zerkale yazyka: pishchevaritel'nyy trakt ["Naive anatomy” in the mirror of the language: the digestive tract]. In: Etnolingvistika. Onomastika. Etimologiya Ekaterinburg [Ethnolinguistics. Onomatology. Etymology]: proceedings of the 3rd international research conference Ekaterinburg, September 7-11, 2015. Ekaterinburg, Izd-vo Ural. un-ta [online] Available at: http://hdl.handle.net/10995/38370 (access date: 03.02.2020).

Kengesbaev, I. K. (2007) Frazeologiialyқ sözdik [Phraseological dictionary]. Almaty, ҚаzАқрarat. 356 p. (In Kaz.).

Klobukov, P. E. (1997) Metafora kak kontseptual'naya model' formirovaniya yazyka emotsiy [Metaphor as a conceptual model of the formation of the language of emotions]. In: Yazyk, soznaniye, kommunikatsiya [Language, consciousness, communication]: collection of articles. Ed. by V.V. Krasnykh and A. I. Izotov. Moscow, Filologiya. Vol. 2. Pp. 41-47. (In Russ.).

Musabekova, U. A. and Kultursynova, F. B. (2018) National and cultural specifics of representation of the concept „HEART"e (on materials of M. Joldasbekov“s works) [National and cultural specifics of concept „JUREK"e representations: the works of M. Zholdasbekov)]. Neophilology, vol. 4, no. 16, pp. 15-19. (In Russ.). DOI: https://doi.org/10.20310/25876953-2018-4-16-15-19.

Ondar, B. K. (2010) Slovo «Serdtse» («Churek») v sostave frazeologicheskikh i nefrazeologicheskikh oborotov russkogo i tuvinskogo yazykov [The word "Heart" ("Churek") as part of the phraseological and non-phraseological units of the Russian and Tuvan languages]. Vestnik Tuvinskogo gosudarstvennogo universiteta. Sotsial'nyye i gumanitarnyye nauki, no. 1 , pp. 124-132. (In Russ.).

Rassadin, V. I. (1988) O tiurkskom vliianii na razvitie govora nizhneudinskikh buriat [On the Turkic influence on the development of the dialect of the Lower Udin Buryats]. In: Problemy mongol'skogo iazykoznaniia [Problems of Mongolian linguistics]: A collection of articles / ed. by L. D. Shagdarov. Novosibirsk, Nauka. 159 p. Pp. 62-75.

Russko-tuvinskii slovar' [A Tuvan-Russian dictionary] (1980) / ed. by D. A. Mongush. Moscow, Russkii iazyk. 664 p. (In Russ. and Tuv.)

Sultangubieva, A. A. (2011a) Dini alemdegi zhurek konceptinin kyzmeti (kazak, orys, agylshyn tilderinin materialdary boyinsha) [The role of the concept of the heart in the religious world: the cases of the Kazakh, Russian and English languages]. Vestnik KazNU. Philological series, no. 2 (132), pp. 165-167. (In Kaz.).

Sultangubieva, A. A. (2011b) Zhurek conceptindegi “adam zhadayynyk fizikalyk kurinisteri” (Kazakh, orys, agylshyn tildernin materialdary boyinsha) ["Physical manifestations of the human condition" in the concept of the heart: the case of the Kazakh, Russian and English languages]. Vestnik KazNU. Philological series, no. 4 (134), pp. 195-198. (In Kaz.).

Sukhorukova, Y. S. (2017) K voprosu o naivnoi anatomii serdtsa vo frantsuzskoi frazeologii [On naive anatomy of the heart in French phraseology]. Filologicheskie nauki. Voprosy teorii i praktiki, no. 3 (69): in 3 parts. Part 3, pp. 168-170. (In Russ.).

Traditsionnoye mirovozzreniye tyurkov Yuzhnoy Sibiri. Znak i ritual [The traditional worldview of the Turks of southern Siberia: The sign and ritual] (1990) / ed. Sagalayev, A. M., Oktyabr'skaya, I. V. Novosibirsk, Nauka. 210 p. (In Russ.).

Tuvinsko-russkii slovar' [A Tuvan-Russian Dictionary] (1968): c. 22000 words / ed. by E. R. Tenishev. Moscow, Sovetskaia entsiklopediia. 465 p. (In Russ. and Tuv.).

Uryson, E. V. (2003) Problemy issledovaniya yazykovoy kartiny mira: Analogiya v semantike [Problems of studying the linguistic world picture: An analogy in semantics]. Moscow, Yazyki slavyanskoy kul'tury. 224 p. (In Russ.).

Davitz, J. R. (1969) The Language of Emotion. New York, Academic Press. 208 p.

Kövecses, Z. (1989) Emotion Concepts. Frankfurt-am-Main: Springer Verlag. 230 p.

Temirgazina, Z., Khamitova, G., Orazalinova, K. (2016) Didactic Features of a Learner's English-Russian Dictionary of Biology Development. Research Journal of Pharmaceutical, Biological and Chemical Sciences, no. 7(2), p. 317-326.

Temirgazina, Z. K., Bahtikireeva, U. M. and Sinyachkin, V. P. (2017) Artifacts as a source of russian and kazakh Zoological terms. Information, vol. 20, no. 4(A), pp. 2325-2336.

Temirgazina, Z., Akosheva, M., Shakaman, Y., Shaharman, A., Kurmanova, Z. and M. Kairova (2019) Metaphors in Anatomical Terminology. Space and Culture, India, no. 7:1, pp. 143-153. DOI: https://doi.org/10.20896/saci.v7i1.528

Submission date: 12.10 .2020 . 